\title{
HEGEMONÍA EMPRESARIA EN EL “ESPLENDOR” Y “OCASO” DE YPF. EL CASO DE LA PETROLERA ARGENTINA.
}

\author{
Hernán M. Palermo ${ }^{1}$
}

\begin{abstract}
"Hemos vivido toda una época de esplendor con YPF estatal. Pero cuando la privatizaron... nos mataron a todos. Todo fue una pérdida ... como una especie de ocaso” (Ex trabajador de YPF. 2009. Campamento Vespucio, Provincia de Salta)
\end{abstract}

\section{Introducción}

La privatización de Yacimientos Petrolíferos Fiscales (YPF) significó un proceso emblemático del avance de las políticas neoliberales. Las leyes de Emergencia Económica y de Reforma del Estado, sancionadas al iniciarse el gobierno de Menem, fueron instrumentos claves que habilitaron la privatización de las empresas públicas productoras de bienes y prestadoras de servicios que fueran propiedad del Estado. En ese contexto, se operó un vuelco profundo y sistemático en la política petrolera. Mediante decretos se trastocó el estatus estratégico que, en el pasado, se había otorgado a los hidrocarburos, incentivando la libre disponibilidad de exportación del petróleo extraído por las empresas privadas. Asimismo, durante este período se consumó una embestida contra la clase trabajadora, edificando un nuevo orden laboral sustentado en la precarización del trabajo en sus múltiples facetas.

Luego del despido sistemático de trabajadores de la empresa estatal YPF, se implementaron nuevas doctrinas manageriales en gran parte de matriz toyotista. Así, tanto en el espacio de la producción como de la reproducción, la disputa económicocultural y política se dirimió en un escenario que racionalizó el trabajo y reconfiguró los territorios en los que se emplazaban áreas de explotación y procesamiento de hidrocarburos.

La problemática del control en los espacios de trabajo ha sido abordada recurrentemente desde la Sociología del Trabajo. No obstante, las relaciones de dominación articuladas dentro y fuera del espacio de trabajo ha sido materia de estudio de la Antropología del Trabajo. En este sentido se destacan autores tales como José Sergio Leite Lopes, quien analiza como el control dentro de los ingenios azucareros en el nordeste de Brasil traspasa los espacios del trabajo "incrustándose" en todos los espacios de la vida de los trabajadores. Esa "invasión” del trabajo en el área doméstica, dirá Leite Lopes, conforma los cimientos del cautiverio de los trabajadores (2011: 133).

\footnotetext{
${ }^{1}$ Universidad de Buenos Aires, Argentina.
} 
Fundamentalmente la investigación de Leite Lopes devela las formas que adquiere el proceso de dominación en el espacio de la reproducción de los trabajadores. Así las representaciones y practicas sociales de los trabajadores se ven atravesadas por los intereses empresarios que desbordan el espacio de la fábrica y se sitúan en todos los aspectos de la vida cotidiana. En la relación entre esfera de reproducción y producción, también encontramos el trabajo de Neiburg (1988) y su análisis del sistema de "fábricavilla obrera" en la empresa Loma Negra. Esta última investigación analiza de manera pormenorizada la configuración de los barrios obreros en una empresa emblemática que fuera propiedad de los Fortabat. June Nash (1989) ha realizado aportes de relevancia al analizar la conformación de la hegemonía empresaria en el nivel de las localidades donde se emplazan grandes empresas. La antropóloga norteamericana incorpora a la clase obrera como sujeto creativo, activo, partícipe en la consolidación de los intereses empresarios. Gustavo Lins Ribeiro a partir de la categoría de "proyectos de grandes obras" otorga elementos sustanciales para abordar la conformación de emprendimientos de gran envergadura (2006, 1991). Retomando a Gustavo Lins Ribeiro, todo proyecto tiene su historia en términos ideológicos. Asimismo, algunos trabajos más recientes indagan los procesos de instalación territorial de empresas del sector público, orientados a la explotación de recursos estrategicos como en el petróleo y el siderúrgico (Palermo y Soul, 2009; Palermo, 2012; Rivero 2008; Giniger, 2011).

En este contexto, de estudios críticos, desde nuestra perspectiva, las nuevas doctrinas manageriales, sus dispositivos y mecanismos, expresan una disputa destinada a sostener la hegemonía empresaria sobre el trabajo. Allí radica una lucha cultural y política que se traduce en la puja por definir los nuevos principios de legitimidad imperantes en las empresas privatizadas de Argentina. Allí también radica la necesaria lectura de las formas sofisticadas en que se ejerce el control y las nuevas matrices de disciplinamiento laboral derivadas de estos procesos. El caso de las empresas privatizadas en general y, en particular la que nos ocupa en este artículo -YPF-, nos aporta elementos emblemáticos para el análisis: se trata de una empresa que sentó bases sólidas para forjar formas de subjetividad laboral sintetizadas en la autodenominación de "ypefeano." Este colectivo de trabajo creció al calor de los valores de "desarrollo," "nación," "progreso social y económico." Así, el control que ejercieron las políticas empresarias de YPF estatal, desbordaron los espacios de la fábrica y se incrustaron en la estructura cotidiana de los trabajadores y en casi todos sus intersticios. El orden laboral 
se recreaba enlazando el espacio de la producción y reproducción, trazando una perspectiva de largo plazo para los trabajadores que, en general, incluía más de una generación laboral entre padres e hijos.

En este artículo se analizan las continuidades y discontinuidades de las formas de control y disciplina de la fuerza trabajo en la etapa estatal de YPF y en la etapa post privatización. Los hallazgos que se derivan de esta investigación pone de manifiesto los principios estructurantes del orden laboral estatal, ${ }^{2}$ su relación dialéctica con la construcción de las experiencias del colectivo de trabajo analizados en clave de comunidad de fábrica (Palermo y Soul, 2009). Desde este escenario se focaliza el sentido y alcance que cobraron las estrategias de racionalización del trabajo destinadas a desestructurar el orden anterior y las herramientas empresariales vitales que se impulsaron para sostener la actual hegemonía empresaria sobre el trabajo.

\section{La empresa estatal YPF: desarrollo nacional y configuración de la experiencia petrolera}

Dadas las características propias de la explotación petrolera, YPF desarrolló regiones alejadas de los grandes centros económicos y urbanos del país -en particular de la Ciudad de Buenos Aires- y dinamizó ciudades que crecieron al calor de sus políticas empresarias. En este sentido, distintas localidades surgieron de la actividad de YPF, de norte a sur, ${ }^{3}$ de este a oeste,${ }^{4}$ conformando regiones enteras subordinadas a la dinámica de la petrolera estatal. Se configuró, así, una estructura económica dependiente del monopolio de esta actividad productiva que incluía otras actividades sectoriales fundamentales en la producción de hidrocarburos. Así, se generaron profundas transformaciones estructurales en las distintas ciudades donde YPF se

\footnotetext{
${ }^{2}$ Esta investigación incluye un extenso trabajo de campo realizado en distintos territorios donde YPF desplegó su acción. Desde el año 2003 estas aproximaciones etnográficas abarcaron la Refinería La Plata (Provincia de Buenos Aires), la Ciudad de Comodoro Rivadavia (Provincia de Chubut), General Mosconi y Campamento Vespucio (Provincia de Salta) y Capital Federal (en la calle Diagonal Norte). El afán de estas tareas radica en la convicción de que es posible comprender e interpretar el significado de YPF para sus trabajadores desnaturalizando las consecuencias que implicó su privatización: para ello es necesario contar con un enfoque que permita apreciar (al menos en parte) el potente despliegue territorial que llevó adelante la empresa en todo el mapa de la Argentina. A raíz de ello, se realizó un importante relevamiento de relatos, tanto de ex trabajadores como de aquéllos que se desempeñan en la empresa en la actualidad. Asimismo, se encaró una extensa recopilación de fuentes documentales, convenios colectivos de trabajo, revistas de circulación interna de la empresa y fuentes hemerográficas.

${ }^{3}$ La zona de Yacimiento Norte incluye ciudades como General Mosconi, Campamento Vespucio y Tartagal entre otras. Estas estan ubicadas en la provincia de Salta. En el sur, Comodoro Rivadavia y Caleta Olivia son ciudades emblemáticas en la explotación petrolera, ubicadas en la región patagónica.

${ }^{4}$ En el este, la Refinería La Plata, uno de los pilares más importantes del desarrollo de YPF, fue inaugurada el 23 de diciembre de 1925 en la ciudad de La Plata. En el oeste sobresalen Lujan de Cuyo en Mendoza, Cutral-Có y Plaza Huincul en Neuquén.
} 
desplegó, tanto en el nivel productivo como en el social y cultural. La petrolera estatal imprimió una marca y dotó de fisonomía a un entramado de relaciones sociales cotidianas mediadas, en gran parte, por la presencia de la empresa. Las políticas de YPF se caracterizaron por establecer un orden sociolaboral dónde el control del espacio del trabajo traspasó las paredes de la "fábrica" y se situó en todas las hendiduras del mundo de la reproducción de los trabajadores y sus familias.

El orden sociolaboral estatal se constituyó a partir de un proceso que estructuró condiciones objetivas y subjetivas. Por un lado, se estableció una profunda segregación jerarquizada del colectivo de trabajo, tanto dentro como fuera de la fábrica; por otro, el trabajo insalubre (propio de la peligrosidad, el desgaste psíquico-mental del trabajo petrolero por turnos) se transformó en una condición estratégica con la estabilidad de la fuerza laboral (el reclutamiento por lazos de consanguinidad y el compromiso de movilidad garantizada). Las regulaciones laborales sancionaron las formas de fijación laboral. La estabilidad y la negociación colectiva contribuyeron a diluir y a naturalizar aquellos procesos que suponían el ejercicio de formas de coacción. Asimismo, estas condiciones formaron una trama con las representaciones de los trabajadores, contribuyendo a la consolidación de las condiciones de producción hegemónicas. Así, la configuración de la comunidad de fábrica sedimentó experiencias de un colectivo de trabajo disciplinado que expresó una potente identificación con la empresa estatal.

\section{a) Dentro de la fábrica}

En términos de la organización del proceso productivo, el orden de YPF implementaba una tajante división del trabajo, propia de la concepción tayloristafordista. ${ }^{5}$ Las formas de control laboral dentro y fuera de los espacios de trabajo se expresaban en una estructura jerarquizada con múltiples niveles de mando. El orden laboral asignó tareas diferenciadas en forma precisa que eran reguladas por convenio colectivo de trabajo.

La marcada diferenciación entre los trabajadores de mando y operarios imprimió profundas huellas fuera de los espacios de trabajo, tanto en la distribución urbanística de

\footnotetext{
${ }^{5}$ Esta división del trabajo entre concepción y ejecución tuvo su correlato en la distribución espacial. La gerencia general se emplazó (aún continúa siendo el centro de decisiones en Argentina) en Diagonal Norte en la capital de Buenos Aires. Allí se establecían las distintas líneas generales en relación a las políticas empresarias vinculados a los planes de producción, inversiones, políticas de exploración, comercialización, formas de intervención en los mercados, etc., que luego se implementaban en las distintas dependencias del país.
} 
los barrios obreros como también en los servicios, que se distinguían según estuvieran orientados para una categoría de trabajador u otra. La distribución urbanística de los barrios "ypefeanos" calcó la profunda segmentación entre trabajadores propia de la esfera de la producción. Es decir, la organización espacial de los barrios de YPF daba cuenta de un continuum atravesado por la lógica de la organización del trabajo, replicando en la arquitectura de los barrios la profunda jerarquización del colectivo obrero. Tanto en Comodoro Rivadavia, en el sur, como en la Administración Norte, la distribución urbanística de los ex barrios "ypefeanos" nos permite reconstruir la profunda jerarquización entre trabajadores de "línea" $\mathrm{u}$ operarios y trabajadores con responsabilidad de mando. En esta segmentación se reconocen beneficios diferenciales, en tanto los barrios de los mandos tenían mejores condiciones de infraestructura y casas más lujosas y espaciosas. Los barrios obreros, los centros de salud, los clubes sociales, los centros de compras (solo para los trabajadores de YPF), fueron algunas de las formas de intervención en los territorios en los que se desplegaba la vida. ${ }^{6}$

El trabajo petrolero históricamente fue y es, hoy día, un trabajo riesgoso, particularmente, para los operarios. Los accidentes producidos solían (y suelen) ser en general, altamente peligrosos para la vida de los trabajadores. A los componentes inflamables propios de esta actividad industrial se le suman, en las tareas de perforación o reparación de los pozos de extracción de crudo, las inclemencias del tiempo. En este sentido, los vientos superiores a los $100 \mathrm{Km}$. por hora que recorren el sur del país, el "frío de infierno" y la nieve, hacen del trabajo en el campo algo sumamente peligroso. En este sentido la experiencia capitalizada en el desempeño del propio trabajo se constituía en un importante reaseguro para enfrentar imprevistos y situaciones potenciales de riesgo.

Otro de los componentes que daban forma al orden laboral de la estatal YPF fue el trabajo en turnos rotativos. Por el mismo proceso de trabajo continuo, los turnos fueron históricamente en la industria petrolera rotativos. Esta forma de organización del trabajo siempre ha trastocado (y lo sigue haciendo en la actualidad) la vida de los

\footnotetext{
${ }^{6}$ En las ciudades donde se desarrolló YPF se generó una profunda tensión entre el colectivo "ypefeano" y el resto de los habitantes. La pertenencia a YPF generaba beneficios como viviendas, lugares de recreación, salarios altos, proveedurías con precios al costo, un sistema de salud y educación, etc., los cuales eran inaccesibles al resto de la comunidad. Este proceso de pertenencia elaboró un nosotros asociado a la empresa que se constituyó sobre la base de un otro que se definía a partir de su no pertenencia. Este proceso de fractura cobró una especial dinámica en el momento de la privatización. Las estrategias de resistencia impulsadas por los trabajadores de YPF, en general, no fueron apoyadas por los habitantes de las ciudades. Este proceso social lo hemos analizado tanto en la ciudad de Comodoro Rivadavia como en General Mosconi o en La Plata.
} 
trabajadores. En este sentido, toda la familia se encontraba condicionada por la organización del trabajo en turnos:

\begin{abstract}
... mi viejo no lo vi nunca. Yo me acuerdo los cumpleaños y todo, y mi papá nunca estaba, sí, siempre laburaba. Y bueh, qué va hacer, te acostumbras. O el domingo que nos reunimos todos, mi viejo...mirá, ¿sabés qué me quedó grabado? El domingo, cuando yo era chico, nos reuníamos a comer, mi hermano con la novia, qué sé yo, nosotros comíamos a la una, mi viejo comía a las 11:30, solo, porque se tenía que ir a laburar. Siempre, toda la vida igual. Nosotros nos sentábamos a comer y mi viejo: "chau, hasta luego". Yo venía del baile, cuando salía que era pibe, venía del baile a las 5 y mi papá ya estaba tomando unos mates y se iba a laburar. Todo así, todo al revés. (Operador de consola, Refinería La Plata).
\end{abstract}

Este relato permite analizar como el trabajo organizado por turnos rotativos imprime profundas marcas, tanto en el tiempo individual como en el tiempo social. El sentido de "todo al revés," como se expresa en el relato, da cuenta de esa contradicción. Se trabaja de noche y se duerme de día a contramarcha de toda la dinámica familiar. Asimismo, el tiempo de trabajo es resignificado como tiempo no compartido por la familia, como tiempo perdido.

El modelo de turno rotativo que se implementaba en la etapa estatal era el $3 \times 8$. Se trabajaba tres mañanas de 5:30 a 13:30h, tres tardes de 14 a $22 \mathrm{~h}$, y tres noches de 22 a 6 h, con un franco y una carga horaria de ocho horas por turno. En la Refinería La Plata $^{7}$ se trabajaba seis horas por considerar que las tareas eran insalubres. Este fue un derecho obtenido por los trabajadores para ciertos sectores altamente contaminados por los químicos o ácidos utilizados. ${ }^{8}$ Sin embargo, el trabajo insalubre y las seis horas para ciertos sectores fueron derogados a partir de la dictadura en $1976 .{ }^{9}$

Teniendo en cuenta la peligrosidad de la actividad, la jornada laboral era un factor central. La misma concepción de turnos rotativos (que trastoca la vida dentro y fuera de la fábrica) se constituye en trabajo insalubre. Así, peligrosidad y extensión de la jornada, expresan condiciones que afectan sensiblemente el tiempo vital. En este

\footnotetext{
${ }^{7}$ El caso de la planta de Lineal Alquilbenceno (LAB) de la Refinería La Plata en la Provincia de Buenos Aires.

${ }^{8}$ La insalubridad para ciertas plantas fue posible a partir del proceso de disputa política de los 1960 y 1970.

${ }^{9}$ La duración de la jornada de trabajo fue uno de los criterios que se modificaron con la privatización. A partir del análisis de las áreas de recursos humanos, se llegó a la conclusión que el turno americano de 12 horas conlleva menos tiempos muertos que el turno de 8 horas. Nuestro trabajo de campo nos permitió entrevistar a aquellos mandos que motorizaron esta transformación y la justificación del cambio se basó en que el turno de 12 horas tiene un solo recambio de trabajadores mientras que el turno de 8 horas implica un recambio de tres trabajadores por día. Entre el trabajador de turno y su reemplazo se generan mayores tiempos muertos.
} 
escenario, la estabilización de la fuerza laboral será materia de gestión específica en el orden laboral.

Las formas jerárquicas se sustentaban en condiciones de contratación estables y en una garantía de movilidad profesional a partir de la antigüedad y la experiencia. El empleo, seguro y estable y la promoción (que implicaba ascensos en niveles jerárquicos y mejoras salariales) fueron configurando un espacio político cultural/identitario que otorgó fisonomía a las experiencias de la comunidad de fábrica. De esta forma, los ascensos previsibles, a partir de la antigüedad y las calificaciones, y la perspectiva de mejoras salariales, vinculadas a la antigüedad, posibilitaban el acceso a puestos con responsabilidad de mando como supervisores y jefes de turno. Es así que la experiencia significaba, a la vez, dominio de las tareas e identificación con determinada cultura empresarial.

La modalidad de reclutamiento de los trabajadores estaba organizada fundamentalmente por un flujo que provenía de sus mismas familias. Los futuros trabajadores de YPF eran aquellos hijos de "ypefeanos" que, en cierto sentido, también experimentaban y vivían la empresa como propia, y gozaban de los beneficios que la petrolera estatal irradiaba para los trabajadores y sus familias. Los lazos de familiaridad estructuraban las formas de reclutamiento en la empresa estatal:

Mis viejos eran de Vespucio, y como la mayoría de las personas, trabajaban en YPF. Mis abuelos también eran de YPF de parte de mi papá, y trabajan desde hace mucho tiempo en YPF. Del lado de mi mamá, también mis abuelos trabajaban ahí. Y los hermanos de mi mamá también. Si no se hubiese vendido [hablando de YPF] mi hermano y yo probablemente también hubiéramos trabajado en YPF. (Hija de ex trabajador de YPF, Campamento Vespucio).

La experiencia de familias enteras que compartían el espacio de la fábrica reforzaba las adscripciones con la empresa. Se dependía plenamente de YPF para sobrevivir y los destinos de los trabajadores estaban sujetos al orden productivo, laboral y cultural imperante en la empresa. La familia como factor estructurante del reclutamiento de los trabajadores expresaba las necesidades propias del orden laboral de YPF. En tanto asegura una fuerza de trabajo sedentaria, la familia se constituyó en materia de gestión estratégica dentro y fuera de la fábrica. Las políticas empresariales 
estabilizaron la fuerza de trabajo en la fábrica, pero también en los territorios en los que desplegó su acción YPF. ${ }^{10}$

Cada generación de nuevos trabajadores procedentes de las familias "ypefeanas" era incorporada a una dinámica laboral totalizadora Esta política contribuyó a edificar y sostener experiencias sociales que significaban a la empresa como propia, de toda la familia. Así, la empresa aportaba el trabajo vital para la reproducción de las futuras generaciones.

Las regulaciones laborales sancionadas en el Convenio Colectivo de trabajo del año 1975, expresaban aspectos nodales del orden laboral que estamos describiendo. Las políticas orientadas a estabilizar la fuerza laboral se reflejan claramente en la norma convencional. El inicio de la relación laboral (y la prioridad de la familia), los criterios para la movilidad, se constituyeron en materias fundamentales de negociación:

\footnotetext{
El ascenso de trabajadores cualquiera sea su categoría y función y la cobertura de la vacante originaria y de las vacantes sucesivas que se produzcan en su consecuencia se realizará ponderando los siguientes requisitos: A) Antigüedad (...). B) Idoneidad (...). C) Existencia o no de sanciones disciplinarias (...). D) Comportamiento laboral (...). (CCT 23/75, Artículo 29).
}

En igualdad de condiciones tendrán prioridad para el ingreso los siguientes aspirantes: A) Esposa o hijos de agentes fallecidos en actos de servicios. B) Esposa o hijos de agentes fallecidos en actividad. C) Hijos del personal jubilado fallecido (casados). D) Hijos del personal jubilado fallecido (solteros). E) Hijos del personal en actividad casados. F) Hijos del personal en actividad solteros. G) Hijos del personal jubilado. H) Trabajadores que se hayan desempeñado o se desempeñen en la empresa a la fecha de suscripción del presente convenio, según relaciones contractuales a plazo fijo o de carácter eventual. I) Familiares de agentes en actividad. J) Familiares de agentes jubilados. (Convenio Colectivo 23/75, art. 8).

La fuerza de lo legal (convenios) y de la legitimidad a través de lo culturalidentitario (como se analiza en la próxima sección) aportaron condiciones propicias para sedimentar un orden laboral aceptado, querido y defendido. Estas condiciones materiales, dinamizadas desde la empresa consolidaron experiencias de un colectivo de trabajo e imprimieron profundas marcas en la subjetividad de los trabajadores.

\footnotetext{
${ }^{10}$ Por ejemplo, en el caso analizado por Gustavo Lins Riveiro (2006) acerca de la construcción de la capital Brasilia en Brasil, las familias representaban un obstáculo a las necesidades de la forma de producción de lo que el autor denominó Gran Proyecto. Es decir, el caso de Brasilia requería, contrariamente a YPF, una fuerza de trabajo con características de transitoriedad, debido a que todo Gran Proyecto posee un tiempo de culminación. A partir de la culminación del Gran Proyecto los trabajadores dejan de ser necesarios para los objetivos del capital y deben abandonar el territorio (2006: 90).
} 


\section{b) Génesis y consolidación de las experiencias del colectivo "ypefeano"}

Las modalidades de gestión del trabajo (que implicaron la estabilización de la fuerza laboral, incluyendo a la familia) y un férreo monitoreo en el espacio de la reproducción por parte de la empresa, aportaron condiciones propicias para dar forma a las experiencias de la comunidad de fábrica (Palermo, Soul, 2009). Esta experiencia incluyó no sólo a los trabajadores "ypefeanos," sino también a las familias, autodenominadas "familias ypefeanas." Se consolidaron así los cimientos de un proceso hegemónico que implicó diversas formas de intervención empresaria en el espacio del trabajo y en los territorios donde YPF se emplazaba. De esta forma, las políticas empresarias contribuyeron a la creación de subjetividades arraigadas en la identificación con la empresa. Las experiencias del colectivo de trabajo se estructuraron sobre la base de mecanismos de identificación con la empresa que se actualizaban en el cotidiano de trabajo y de la vida en general.

El Estado empresario que "vigila" y "protege," la defensa (en clave de soberanía nacional) del petróleo como recurso estratégico, ${ }^{11}$ no renovable y una política de "desarrollo nacional" se constituyeron en sentidos nodales transformados en la matriz de las experiencias de los trabajadores "ypefeanos."

Si le iba bien a la empresa le iba bien a todo país. Eso no tengas dudas... si YPF se desarrollaba y crecía, en cierto sentido crecíamos todos. (Ex trabajador de YPF, Refinería La Plata).

El hecho de que sea estatal, una industria que desarrollaba el país... qué se yo... tenía otro valor...Y respecto al trabajo, como que el Estado mismo a través de su estructura te daba trabajo, como si fuera un papá YPF. (Ex trabajador de YPF, Refinería La Plata).

El destino individual/familiar se enlazaba al futuro empresarial/regional/nacional. YPF asumió un rol fundacional. Así, los “ypefeanos” se situaron como parte de un proceso de trabajo que se relacionó directamente con la construcción de la "patria" y la "nación". YPF era pionera y este carácter asociado a la

\footnotetext{
${ }^{11}$ Desde antes de la construcción de YPF en 1922, la discusión en torno del recurso hidrocarburífero como bien estratégico vinculado al desarrollo, la independencia económica y la soberanía nacional, formaba parte de las ideas de cierto sector de Ejército Argentino (Rouquié, 1986; Potash, 1941). Alain Rouquié (1986) analiza cómo esta vocación industrialista y nacionalista de una parte del Ejército se fundaba en lo que algunos medios militares llamaron las "dependencias críticas." Es decir, estos sectores, con una fuerte influencia en las políticas estatales, tanto en los gobiernos de Yrigoyen (1916-1922 y 1928-1930) como con Alvear (1922-1928), marcaban la fragilidad de la Argentina ante una potencial situación de guerra. En este sentido, YPF conformaba un pilar central para esta facción del ejército donde sobresalía la figura del General Mosconi.
} 
idea de desarrollo y progreso aportó un sentido totalizante que tejía certeramente el tiempo biográfico con el tiempo social, el origen con el futuro, la innovación con el desarrollo. Estado empresario, nación y desarrollo se afincaron con fuerza en el sentido común de los "ypefeanos."

Mi viejo era de esos trabajadores que la sentían como propia a la empresa. Una empresa que era un poco de todos... es por eso que cuando lo rajaron no lo podía creer, para él YPF era eterno. (Hijo de ex trabajador de YPF, Comodoro Rivadavia).

Las políticas empresarias contribuyeron a la reificación del conflicto capitaltrabajo. Así, las relaciones de clases estuvieron signadas por la experiencia del patrón ausente (Soul, 2009) o desde la perspectiva de los trabajadores: una empresa "sentida como propia." Las experiencias de patrón o dueño ausente, se extendieron en los distintos territorios donde YPF desplegó su acción. De este modo, el rol social que impulsaba la empresa se asoció a una política de desarrollo regional:

Esos árboles que vos ves allá los plantó todos YPF... ahora no hacen más nada, solo se llevan la guita... antes la guita quedaba acá. (Ex trabajador de YPF, Comodoro Rivadavia).

En nuestro trabajo de campo, mientras recorríamos la ruta que une General Mosconi y Campamento Vespucio en la provincia Salta, el relato de un ex trabajador de YPF ejemplificaba de forma potente el sello que imprimió YPF en el territorio.

\begin{abstract}
Esto está medio, todo hecho mierda... Esta ruta está toda rota. ¡Todo esto cuando estaba YPF no era así, era una autopista, estaba todo impecable!... Todo, todo el pavimento que va a Vespucio era una maravilla. YPF por ejemplo, hacía un camino y reforestaba. El camino este por el que pasamos nosotros. Ahora son todas empresas privadas que pertenecen a la Pluspetrol, Tecpetrol. ${ }^{12}$ (Ex trabajador de YPF, General Mosconi).
\end{abstract}

En las entrevistas realizadas a ex trabajadores de YPF en distintas regiones, el rol social de la empresa estatal contrasta, como el negativo de una foto, con el contexto post privatización. Aquello que cobra protagonismo es la presencia del patrón presente: "los españoles."

12 Tecpetrol y Pluspetrol son empresas en las cuales Repsol posee acciones. Ambas mantienen en la actualidad una presencia importante en el norte del país, particularmente en General Mosconi, Vespucio y Tartagal. 
Lo que pasa que acá, lo que están haciendo los gallegos hoy por hoy en día es llevarse todo el petróleo, y a la larga lo que te van a dejar es el cascarón. Te van a dejar los caños, las bombas, y de que te sirve si vos no tenés la materia prima que es el petróleo. (Ex trabajador de YPF, Refinería La Plata).

El rol social de YPF imprimió una profunda huella en las experiencias de los trabajadores. Asimismo, esta potente identificación generó en ellos una motivación extra al momento de realizar el trabajo. Como la empresa era "un poco de todos," el éxito, ligado al desarrollo nacional, era también "de todos."

... mi viejo se hizo la casa laburando en YPF, crió a sus hijos laburando en YPF. Entonces cómo que lo llevaban en el corazón a YPF. Mi papá, creo que en 40 años, faltó seis días enfermo, no una cosa de locos, era su empresa más o menos. Faltó por que estaba casi muerto, por que hasta muerto ha ido a laburar. Es que había otra relación con $Y P F$, ¿no? (Actual operador, Refinería La Plata).

Si YPF era "de todos" había, entonces, que demostrarlo en el día a día, en el espacio de trabajo:

Yo me sentía parte estando en YPF, decíamos una hora de servicio da tantos millones de dólares, la unidad no puede estar parada 4 meses. Nos juntamos entre los compañeros... ¿qué hacemos? Este catalítico no puede estar parado. Juntémonos todos, hagamos organigramas, unos con otros, para que no se choquen y hacer andar el catalítico. No sabes, hemos logramos reducir de esos 40, 60 días a 28 días la parada del catalítico, un mes como máximo. Se ponía alma y vida ahí. También estaba el gerente. (Ex operador de campo, Refinería La Plata).

Sin embargo, a pesar que el discurso privatista neoliberal consolidó en los años noventa una retórica ligada a la "vagancia" y a la "indisciplina" de los trabajadores de YPF, subsiste como valor, tanto en ex trabajadores como en quiénes aún mantienen sus puestos de trabajo, el "orgullo petrolero."

Cuando hablo del trabajo en YPF lo hago con un fuerte orgullo. Hacíamos un laburo único. Enfrentábamos frentes de fuego, era un laburo súper riesgoso. Muchos compañeros quedaron en el campo. (Ex trabajador de YPF, Comodoro Rivadavia).

El orden sociolaboral de YPF estatal llevó varias décadas de consolidación en los territorios donde la empresa petrolera se desarrolló. Al menos entre dos y tres generaciones de trabajadores formaron parte de la experiencia de ser un trabajador "ypefeano." Desde mediados de 1970 se inicia un proceso que modificará sustancialmente el orden laboral estatal. La racionalización en los noventa, en el marco 
del proceso privatizador, desplegará variadas estrategias que desestructuraron las bases de sustento del viejo orden. Se instituye así la modernización empresaria que trastoca de raíz el orden productivo laboral y cultural.

\section{Reconfiguración de la hegemonía empresaria sobre el trabajo}

La privatización de YPF culminó a fines de la década de 1990 y forma parte de un proceso político iniciado desde mediados de los años 1970. La dictadura militar, el Estado rentista y los procesos de liberalización tejerán un hilván certero que se despliega con el "menemato" en la década de 1990. Una férrea persecución a la clase trabajadora y un proceso de desarticulación del entramado industrial fueron dos caras de la misma moneda que se constituyeron en potentes herramientas de disciplinamiento en el "suelo de fábrica." Este escenario significó una metamorfosis (Bonnet, 2008) en las formas de intervención institucional de las políticas estatales, marco en el cual las privatizaciones fueron instrumentos emblemáticos. Los procesos de modernización empresaria, laboral y educacional fueron el andamiaje central desde el cual recomponer las formas hegemónicas del capital sobre el trabajo. Sin embargo, este proceso requirió sofisticar los dispositivos de control y de disciplina social, cultural y laboral.

En este contexto, el proceso privatizador de YPF, iniciado en 1989 con el Plan de Transformación Global, ${ }^{13}$ concretado en 1999 con la venta de casi la totalidad del capital accionario a la empresa española Repsol, ${ }^{14}$ constituye desde nuestra perspectiva un caso paradigmático.

El período de mayor represión, persecución y despidos de los trabajadores se llevó a cabo al iniciar la década de los noventa. Se implementó una profunda transformación en las políticas empresarias tendientes a desestructurar el viejo orden laboral, profesional y cultural. Durante el período de 1990 a 1995 se realizaron las transformaciones más profundas, fraguando las bases de una nueva arquitectura empresaria. La exclusión sistemática de trabajadores mediante los "retiros

\footnotetext{
${ }^{13}$ El decreto número 2.778/90 firmado el 31 de diciembre de 1990 denominado "Plan de Transformación Global" dispuso que YPF Sociedad del Estado (S.E.) se constituyera en Sociedad Anónima (S.A.) abriendo la posibilidad de la venta accionaria de la empresa. Este decreto fue la piedra fundante de la privatización de YPF.

${ }^{14}$ A fines del año 1999 la empresa española Repsol concreta la adquisición del 98.23\% de las acciones de YPF.
} 
voluntarios," ${ }^{15}$ la tercerización y la implementación de aggiornados dispositivos de control y disciplina laboral, la instrumentación de las nuevas doctrinas corporativas, serán herramientas de gestión claves en el proceso de racionalización y consolidación de la hegemonía empresaria sobre el trabajo.

En este contexto, el viejo orden sociolaboral se erosionaba y, con ello, todos los pilares que lo sustentaban. El nuevo orden se impuso de forma abrupta, impensada para los trabajadores. En pocos años se llevó a cabo en YPF un proceso de desarticulación del entramado social que conformó la denominada comunidad de fábrica. Este proceso se apoyó en la exclusión sistemática de trabajadores, la fragmentación de los colectivos obreros (sobre todo a partir de la tercerización de funciones clave como el mantenimiento), la erosión de los sentidos de "estatalidad" y "nación" detrás de la actividad del petrolero, la supresión de aquellas políticas que desbordaban el espacio de trabajo y se situaban en la vida cotidiana de los trabajadores y sus familias. En los contornos de la nueva morfología del trabajo (Antunes, 2005; 2006; 2009), delineado en la década de 1990, la identificación con la empresa sintetizada en la auto adscripción "ypefeana" se tornó obsoleta a los intereses empresarios. En su publicación corporativa, YPF lo expresaba en forma clara y violenta a la vez:

\begin{abstract}
... el viejo pacto nunca escrito pero que siempre intercambió lealtad a la compañía por seguridad en el puesto de trabajo. Este pacto ha muerto... La tolerancia de las empresas ante empleados improductivos llevaba a acuerdos tan espurios como degradantes. (O' Reilly, Brian. "El New Deal entre empresas y empleados." En: Revista Comunicación YPF, $\mathrm{n}^{\circ} 328$. Agosto de 1994).
\end{abstract}

La nueva gestión del trabajo rediseñada a partir de las nuevas doctrinas corporativas transmiten mecanismos de cooptación sostenidos sobre bases inéditas en la relación laboral. El nuevo modelo identificatorio se sustentará en la colaboración de cada trabajador con la empresa y la competencia entre trabajadores

\title{
a) Despidos y recambio de la fuerza de trabajo
}

El significante "sobrecapacidad" comenzó a formar parte del cotidiano de trabajo. La Revista Petrotécnia, de circulación interna en la empresa, comenzaba a situar en la primera plana esta noción.

\footnotetext{
${ }^{15}$ Los retiros voluntarios fueron despidos compulsivos. El eufemismo de los "voluntario encubrió las presiones y persecuciones que sufrieron los trabajadores para firmar los despidos.
} 
Las compañías se están racionalizando y contrayendo, minimizando riesgos alejándose de las inversiones en muy grandes refinerías. Aún así la sobrecapacidad todavía existe. (Revista Petrotecnia. Instituto Argentino del Petróleo. Año XXXI n. ${ }^{\circ}$ 1. Enero-Febrero de 1990).

A partir del supuesto de "sobrecapacidad de trabajadores" se implementó una política de racionalización. Fueron excluidos quiénes no serían parte del proyecto privatista/modernizante. En este contexto, se elaboraron distintas estrategias que redujeron el plantel en menos de 4 años tanto que, entre los años 1990 y 1994, la población ocupada se contrajo desde 36.935 a 5.860 trabajadores. Es decir, en solo tres años, la efectiva racionalización alcanzó un $84,1 \%$ del plantel. El paquete de políticas de racionalización de trabajadores que se implementó en YPF constó de varias estrategias. El eufemismo "retiro voluntario" fue una de las opciones más extendidas. Fueron verdaderos despidos encubiertos que se implementaron bajo un clima de presión y persecución de las jefaturas hacia los trabajadores donde casi no existía alternativa de elección.

\begin{abstract}
Me agarró uno de las jefaturas y me dijo que si no firmaba el retiro me iba a ir sin cinco centavos. Yo quise hablar con el delegado en ese momento y estaba muy ocupado, no me pudo atender. No me podían atender. Había una confusión bárbara, los rumores pasaban por todos lados... Entonces, ante la alternativa [refiriéndose al retiro voluntario] quería hablarlo con mi señora, le digo, 'mirá déjame pensar un cachito.' Me dice: 'no, lo tenés que resolver ya.' 'No pará, voy a tomar un café, voy a respirar un poco, por que me agarrás de improvisto.' 'Bueno, pero tenés que venir esta tarde, me dice. Bueno no estuve bien asesorado... ante la alternativa que me iba a ir con cinco guita como decía el tipo, agarré muy de mala gana pero agarré. (Ex trabajador de YPF de la flota de barcos).
\end{abstract}

Entre los años 1990 y 1994 fueron racionalizados 35.689 trabajadores. Este proceso se llevó a cabo principalmente durante los años 1991 y 1992, cuando se concretó el 70\% del total de los despidos. A causa de este fenómeno, la desocupación en aquellas regiones donde se privatizaba YPF ascendía a niveles inéditos en comparación con la desocupación general de la Argentina. Comodoro Rivadavia y General Mosconi, donde el desempleo y el subempleo se tornaron estructurales, se convirtieron en las localidades con el mayor índice de desocupación del país. Comodoro Rivadavia, una de las ciudades donde más impactó el proceso de privatización de YPF, alcanzó en 1993 el 14,8\% del índice de desempleo, el más alto en toda la Patagonia y en el país en ese momento (Marques, 1997). En 2001 los índices de desocupación generales de la Argentina aumentaban y en aquellas zonas donde se había llevado adelante la privatización de YPF saltaban a niveles altísimos. Las regiones que mejor ilustraron esta 
situación fueron General Mosconi y Tartagal, con el 42,8\% de desocupación para ese año (Svampa y Pereyra, 2003).

La política de racionalización incluyó persecución, hostigamiento y solidaridades de la patronal con las fuerzas represivas que velaban por el orden empresarial. Durante esos años, parte de la radiografía cotidiana era la presencia de la prefectura en la puerta de las dependencias de la empresa, por ejemplo en la Refinería La Plata en la Provincia de Buenos Aires. Las listas "negras"con los nombres de los trabajadores despedidos filtraban a quiénes ya no serían parte de la empresa y este rol era realizado por la Prefectura.

En pocos años el orden sociolaboral se transformó desestructurando la totalidad de las relaciones que sostenían la comunidad de fábrica. El desmoronamiento del “colectivo ypefeano” implicó múltiples fracturas en distintos planos a la vez: los que "quedaron afuera" y los que "quedaron dentro" de la empresa constituyó la primera gran fractura. Entre los que se fueron, se han construido percepciones sobre los que se quedaron, acusándolos de "transar con la patronal" o "vender compañeros para quedarse."

Dentro del "suelo de fábrica" la fragmentación se potencia a partir de la política de tercerización que sustentará, de allí en más, el nuevo orden sociolaboral. En este sentido, el conflicto capital-trabajo se inviste de un conflicto "trabajo-trabajo" generando un enfrentamiento horizontal al dividir dos categorías de trabajadores: los estables y los tercerizados.

\section{b) La nueva doctrina corporativa: tercerización y disciplinamiento laboral}

La tercerización se constituye en uno de los pilares que estructuran el orden laboral post-privatización y, junto a las estrategias de cooptación que desarrolla la patronal, contribuyen a sostener la nueva hegemonía empresaria sobre el trabajo.

A partir del nuevo orden sociolaboral se externalizan funciones claves, reteniendo aquellas que se consideran estratégicas y rentables. Una de las formas de externalización de la fuerza de trabajo fueron los llamados emprendimientos organizados por ex trabajadores de YPF impulsados por el sindicato ${ }^{16}$.

\footnotetext{
${ }^{16}$ Algunos ex trabajadores de YPF, luego del cobro de los retiros voluntarios y asesorados por la empresa y el sindicato, formaron emprendimientos con variadas formas jurídicas, como SRL o cooperativas, etc. Estos trabajadores, a partir de la conformación de emprendimientos, comienzan a vender un "servicio" tercerizado que antes realizaban a partir de una relación formalizada con la empresa como trabajadores de planta. Muchos de estos emprendimientos naufragaron sin remedio debido a múltiples factores tales como
} 
La tercerización impone nuevas reglas en el orden sociolaboral de la empresa privatizada. Fractura aquel colectivo de trabajo identificado con la empresa, instaurando una experiencia laboral atravesada por una profunda heterogeneidad en las formas de contratación y uso de la fuerza de trabajo.

En la cotidianeidad del proceso de trabajo co-existen los trabajadores de YPF Repsol y los trabajadores de las empresas contratistas. Entre unos y otros se genera una profunda división cristalizando la diferenciación del colectivo de trabajo. Los que pertenecen a YPF Repsol son los "propios" mientras que los trabajadores tercerizados son de "las empresas," unos y otros comparten un mismo espacio laboral y conforman un colectivo de trabajo atravesado por condiciones materiales diferentes.

... hay diferencia entre un contratado y un propio. El sueldo no mucho, pero... es diferente. Si vos entrás a laburar con YPF tenés una seguridad laboral. Nosotros nunca sabemos. Eh... en YPF la única forma que te echen es robando, nada más... Yo por ejemplo tengo 20 días de vacaciones, ellos en vez de sacar los veinte corridos sacan de a cuatro. Entonces tiene cuatro francos, las cuatro guardias y vacaciones. Y vos decís: '¿mono?, dos meses estás de vacaciones.' Las reparten en el año, no lo hacen todo seguido en el verano. Vos decís eso pasa en una empresa y te dicen, ' ¡volá ya!'. Pero en ellos está bien. ¿Entendés?, así son los propios. (Trabajador tercerizado, Refinería La Plata).

... en el sector nuestro nos llevamos muy bien con los muchachos de las empresas, en otros los discriminan más, qué sé yo los tratan mal viste, nosotros no, los tratamos como si fuesen uno más. (Operador de campo, Refinería La Plata)

En el mismo espacio laboral co-existen trabajadores de distintas empresas que pertenecen a distintos gremios, con convenios y remuneraciones diferentes y condiciones de trabajo totalmente asimétricas o, en el peor de los casos, con oficios similares trabajando en el mismo lugar pero con condiciones desiguales.

Estas diferencias entre los "propios" y los de "las empresas" se extienden fuera del "suelo de fábrica." Es decir, ser parte de los "propios" o pertenecer al grupo de "las empresas" imprime su matriz en las redes de sociabilidad fuera del trabajo, dejando marcas en la vida cotidiana de los trabajadores.

... bueno yo el sábado tuve un asado, todas las empresas de asfaltos, sólo contratados. No vino uno (haciendo referencia a un trabajador de YPF). Nadie te dice: 'che negro'... hay pibes re copados propios, toda la onda, pero no, no. Quizás hasta el mismo contratado... El muchacho que hizo el asado,... vino ahi a mantenimiento y fue atrás del cargadero y dijo: 'Bueno loco, va a ver lechón,

la falta de experiencia empresaria de los ahora "socios empresarios" o porque tuvieron que competir con empresas más eficientes y con amplia trayectoria en el negocio petrolero. 
costillar, pago yo, vamos todos,' fuimos todos. No vino uno solo de YPF. (Trabajador de empresa tercerizada, Refinería La Plata).

Así, la producción de la "otredad" se instala entre los trabajadores, fragmentando los colectivos de trabajo, individualizando las relaciones laborales y reificando el conflicto capital-trabajo que se reconfigura en un conflicto "trabajotrabajo.” Esta tensión dentro del espacio de las tareas es, además, recreada en la misma esfera de la reproducción de los trabajadores.

La fragmentación propiciada por la estrategia de tercerización se conjuga certeramente con la apuesta homogeneizante de las nuevas doctrinas corporativas. La búsqueda de cooptación en el marco de la reconfiguración de la hegemonía empresaria se apoya, a la vez, en una nueva gestión del trabajo que redefine los criterios valorizados en el reclutamiento y la movilidad profesional y, a la vez, promueve potentes dispositivos de control para transponer los sentidos oficiales que subyacen en las nuevas doctrinas corporativas. Es por ello que la creación de nuevas subjetividades en el trabajo significó desmantelar las experiencias construidas en torno de la comunidad de fábrica.

Antes, la experiencia configurada en tanto comunidad de fábrica se sustentaba en un eje articulador: estabilidad en el empleo y el desarrollo profesional a partir de una carrera interna, del rol de la familia en el entramado laboral de la empresa, de una previsibilidad de largo plazo, junto con una potente intervención de la empresa en el plano de la cotidianeidad.

Con la privatización, el lazo que vertebraba aquellas identificaciones se quiebra a partir del impulso de las nuevas doctrinas corporativas. Estas últimas potencian la competencia entre los trabajadores y el sentido de la "proactividad" que, desde la lógica empresaria, se comprende cómo una constante revalorización de los intereses corporativos en las acciones de los trabajadores y la variabilidad salarial a partir de la evaluación de los desempeños.

Así, diversas condiciones objetivas que dotan de fisonomía a una nueva gestión del trabajo, cambios en los criterios de reclutamiento y movilidad profesional, se articulan con una nueva "formación discursiva" que requiere ser transpuesta a partir de programas eficaces de re-profesionalización de la fuerza laboral. Con el nuevo orden empresario proliferan doctrinas manageriales que son ejecutadas y transmitidas a través de la agencia de recursos humanos que desempeña un papel central en el diseño de una nueva arquitectura laboral y profesional. 
Si la doctrina corporativa se orienta hacia la homogeneidad en post del orden y su sostenimiento, la externalización de la fuerza de trabajo segmenta a los trabajadores e instituye la heterogeneidad. La nueva arquitectura empresaria se sustenta en una dialéctica entre homogenización y diferenciación, contribuyendo a la reificación del conflicto capital- trabajo.

\section{Conclusiones}

La privatización de YPF fue impulsada a partir de una combinatoria de estrategias gubernamentales y empresariales que modificaron sustancialmente el orden laboral pre-existente. Con este fin, la operatoria empresarial puso en marcha un profundo proceso de racionalización laboral que persiguió un claro propósito: operar casi por sustitución de la fuerza laboral. Este recambio fue acompañado por la instalación de nuevos principios que estructurarían, desde inicios de los 1990 en adelante, el orden laboral, profesional y cultural.

Bajo el orden estatal, la hegemonía empresaria se consolidó al amparo de una gestión del trabajo que estabilizó a la fuerza laboral y, a la vez, definió una estructura jerárquica funcional de mandos segmentada. Estos principios se articularon con una política de ingreso extendida a las familias y con un control de la empresa en la esfera de la reproducción social. Así, las estrategias de gestión del trabajo (tributarias de un orden político que requiere ser reenviado a la esfera societal), coadyuvaron en el impulso de una comunidad de fábrica fuertemente tejida por identificaciones con otros trabajadores (muchos emparentados por lazos consanguíneos) y con la empresa. La identificación con la empresa expresaba un sentido más denso relacionado con la idea de "nación," “desarrollo" y "progreso" que se asentaba también en la referencia a la independencia y al papel fundacional que había jugado YPF como impulsora de una política de desarrollo nacional. La racionalización durante los primeros años de la década de 1990 y, luego, el impulso de variadas estrategias de gestión para recomponer la hegemonía empresaria sobre el trabajo, asumió un carácter sistémico a la vez que orientó el accionar en un plano material/simbólico cultural. También redefinió la naturaleza y alcance de las actuaciones empresariales dentro y fuera de la fábrica.

La batalla cultural significó sentar nuevos principios de legitimidad operando no sólo en la edificación de un nuevo orden empresario sino también en la creación de nuevas subjetividades. Los análisis desarrollados colocan en evidencia el sentido 
estratégico que significó el proceso de tercerización de la fuerza laboral (para desarrollar funciones que antes se realizaban como tareas centrales en la empresa y con trabajadores que tenían una relación formal estable). La estrategia de tercerización operó directamente sobre la reducción del costo laboral, deslindando responsabilidades empresarias con relación a estos trabajadores precarizados. Pero también asestó un duro golpe en los colectivos de trabajo, instalando la individualización y fragmentación laboral.

\section{Referencias}

ANTUNES, R. Los sentidos del trabajo. Buenos Aires: Herramienta, 2005. ANTUNES, R. Riqueza e Miseria do Trabalho no Brasil. Brasil: Boitempo, 2006. ANTUNES, R. "O trabalho, sua nova morfologia e a era da precarização estrutural". En: Revista Theomai. Estudios sobre Sociedad y Desarrollo. n. 19. Buenos Aires: UNQ, 2009. p. 47-57. Disponible: http://revista-theomai.unq.edu.ar/NUMERO19/contenido_19.htm. BONNET, Alberto. La hegemonía menemista. El neoconservadurismo en Argentina, 1989-2001. Buenos Aires: Prometeo Libros, 2008.

GINIGER, Nuria. “Así se templó el acero”. Estrategias de control laboral y respuestas sindicales en el emplazamiento sidero metalúrgico de Villa Constitución. Implicancias dentro y fuera de la fábrica. Tesis Doctoral. Facultad de Filosofía y Letras. Buenos Aires: UBA, 2011.

GRAMSCI, Antonio. La política y el Estado moderno. Barcelona: Editorial Planeta Agostini, 1985.

GRAMSCI, Antonio. Antología. Selección, traducción y notas de Manuel Sacristán. México: Siglo XXI, 1992.

LEITE LOPES, José Sergio. El vapor del diablo. El trabajo de los obreros del azúcar. Buenos Aires: Editorial Antropofagia, 2011.

MARQUES, Daniel. "Crisis Ocupacional y programas para la generación de empleos: Algunos indicadores para en análisis de Comodoro Rivadavia". En: SALVIA, Agustín y PANAIA, Marta. (comp.). La Patagonia Privatizada. Buenos Aires: Colección CEA CBC, 1997.

NASH, June. From Tank Town to High Tech. The clash of community and industrial cycles. New York: State University of New York, 1989.

NEIBURG, Federico. Fábrica y Villa Obrera: historia social y antropología de los obreros del cemento. Tomo 1 y 2. Buenos Aires: Centro Editor de América Latina, Biblioteca Política Argentina, 1988.

PALERMO, Hernán M. y SOUL, Julia. "Petróleo, acero y nación. Una aproximación antropológica a los procesos sociopolíticos de los colectivos de trabajo de YPF y SOMISA”. En: SCHNEIDER, Alejandro (comp.). Trabajadores. Las experiencias de la clase obrera en Argentina en la segunda mitad del siglo XX. Buenos Aires: Herramienta, 2009.

PALERMO, Hernán. M. Cadena del oro negro en el esplendor y ocaso de YPF. Buenos Aires: Antropofagia, 2012.

POTASH, R. El ejército y la política en la Argentina. Buenos Aires: Hyspamérica, 1985. RIBEIRO, Gustavo Lins. Empresas transnacionais. Um grande projeto por dentro. Brasil: Marco Zero e Anpocs, 1991. 
RIBEIRO Lins, Gustavo. El capital de la esperanza. La experiencia de los trabajadores en la construcción de Brasilia. Buenos Aires: Antropofagia, 2006.

RIVERO, Cynthia. Entre la Comunidad del acero y la Comunidad de María: un análisis antropológico sobre los avatares sociopolíticos de San Nicolás. Buenos Aires: Editorial Antropofagia, 2008.

ROUQUIÉ, A. Poder Militar y sociedad política en la Argentina. Buenos Aires: Hyspamérica, 1986.

SOUL, Julia. “'Acá lo que cambió todo fue la privatización...' Aproximación antropológica a las prácticas obreras en los espacios laborales en procesos de privatización y reconversión productiva". En: Revista Theomai, Estudios sobre Sociedad y Desarrollo, n. 21. Buenos Aires: UNQ, 2009. Disponible: http://revistatheomai.unq.edu.ar/NUMERO\%2021/contenido_21.htm.

SVAMPA, Maristella y PEREYRA, Sebastián. Entre la ruta y el barrio. La experiencia de las organizaciones piqueteras. Buenos Aires: Ed. Biblos, 2003.

WOLF, Eric. Figurar el Poder. Ideologías de dominación y crisis. México: Ediciones de la Casa Chata; CIESAS, 2001. [Primera edición en inglés, Envisioning power: ideologies of dominance and crisis, 1998]. 